See discussions, stats, and author profiles for this publication at: https://www.researchgate.net/publication/282436355

\title{
Developmental changes associated with cross-language similarity in bilingual children
}

Article in Journal of Cognitive Psychology · September 2015

DOI: $10.1080 / 20445911.2015 .1086773$

CITATIONS

6

3 authors:

Ton Andoni Duñabeitia

Nebrija Universidad

135 PUBLICATIONS 2,402 CITATIONS

SEE PROFILE

7. Aina Casaponsa

Lancaster University

10 PUBLICATIONS 65 CITATIONS

SEE PROFILE

Some of the authors of this publication are also working on these related projects:

Project Phonological and orthographic coding in skilled deaf readers View project
READS

266

Lela Ivaz

Basque Center on Cognition, Brain and Language

4 PUBLICATIONS 24 CITATIONS

SEE PROFILE 
Jon Andoni Duñabeitia

Lela Ivaz

Aina Casaponsa

BCBL. Basque Center on Cognition, Brain and Language; Donostia, Spain

Contact information:

Jon Andoni Duñabeitia

Basque Center on Cognition, Brain and Language (BCBL)

Paseo Mikeletegi 69, 2

20009 Donostia, SPAIN

j.dunabeitia@bcbl.eu

+34943309300 (ext. 208)

Acknowledgements: This research has been partially funded by grants PSI2012-32123 from the Spanish Government, ERC-AdG-295362 grant from the European Research Council, and by the AThEME project funded by the European Union (grant number 613465). 
Abstract: The main goal of the present study was to investigate how the degree of orthographic overlap between translation equivalents influences bilingual word recognition processes at different stages of reading development. Spanish-Basque bilingual children with ages ranging from 8 to 15 years were tested in an explicit translation recognition task with a large set of items. Critically, the degree of cross-language similarity (i.e., the cognate status) between the references and the correct targets was manipulated along a continuum in order to investigate how the reliance on cross-language orthographic overlap varies as a function of reading experience. Results showed that younger children were significantly more sensitive to the cognate status of words than older children while recognizing translation equivalents, and that this difference did not depend on the speed of response of the participants. These results demonstrate that the influence of cross-language similarity progressively diminishes as a function of increased exposure to print together with the maturation of the mechanisms responsible for language interference suppression, as suggested by developmental models of bilingual lexical access.

Short title: Cognate effects during childhood.

Keywords: Translation recognition; Cognate words; Reading development; Cross-language interactions; Orthographic processing. 


\section{Introduction}

Numerous recent studies have explored how bilingual individuals process words in their languages at different stages of language consolidation and proficiency, and several factors have been found to modulate bilingual word recognition. Bilingual lexical access largely depends on second language (L2) proficiency and on the age of L2 acquisition (see van Hell \& Tanner, 2012, for a review), the combination of languages at hand and their orthographic distance (e.g., same script vs. different script; see Chen, \& Ng, 1989; Dimitropoulou, Duñabeitia, \& Carreiras, 2011a; Gollan, Forster \& Frost, 1997; Wu \& Thierry, 2010), or the orthotactic rules that govern each of the languages and the language-dependent orthographic regularities (e.g., Casaponsa, Carreiras \& Duñabeitia, 2014; Vaid \& Frenck-Mestre, 2002; Van Kesteren, Dijkstra, \& Smedt, 2012). At this regard, research on the processing of translation equivalents has become essential for our understanding of how bilinguals process print in different languages. Translation equivalents are words that belong to different languages but that denote the same concept, and they can vary in the degree of orthographic and/or phonological overlap, going from non-overlapping representations (e.g., the Spanish-English translation equivalents playa-beach), to completely overlapping word forms (e.g., the Spanish and English words detective).

One of the most interesting findings from studies on bilingual word processing is the degree of automaticity with which bilinguals activate translation equivalents when reading words in one of their languages (e.g., Basnight-Brown \& Altarriba, 2007; Dimitropoulou, Duñabeitia, \& Carreiras, 2011a, 2011b; Duñabeitia, Perea, \& Carreiras, 2010; Duyck \& Warlop, 2009; Grainger \& Frenck-Mestre, 1998; Schoonbaert, Duyck, Brysbaert, \& Hartsuiker, 2009; Schoonbaert, Holcomb, Grainger, \& Hartsuiker, 2010; Thierry \& Wu, 2007). In this vein, recent behavioral studies have shown that it is easier to recognize native (L1) and non-native (L2) 
words when they are preceded by their translation equivalents in the form of briefly presented primes (e.g., masked priming paradigm). Interestingly, this facilitation effect for translation equivalents has been shown to depend on several factors such as L2 proficiency, translation direction and sub- and supra-lexical properties of translation equivalents. It has generally been found that the influence of the L1 over L2 word processing is significantly greater than vice versa when it comes to translation recognition in unbalanced bilinguals, giving rise to a translation direction asymmetry which only disappears at L2 native-like levels of proficiency (see Dimitropoulou et al., 2011a, 2011b; Duñabeitia, Perea, \& Carreiras, 2010; Schoonbaert et al., 2009). While balanced simultaneous bilinguals automatically activate translation equivalents to the same extent when reading words in any of their languages independently of the translation direction, at lower levels of L2 proficiency the translation facilitation effects are mainly found in the L1-L2 direction (e.g., De Groot \& Nas, 1991; Dimitropoulou et al., 2011a; Gollan, et al., 1997; Jiang \& Forster, 2001; Kim \& Davis, 2003; Williams, 1994) and only a few studies have found a translation facilitation effect in the L2-L1 direction (Dimitropoulou et al., 2011b; Duyck \& Warlop, 2009; Schoonbaert et al., 2009; Schoonbaert et al., 2010).

Moreover, it has been shown that the translation facilitation effects are also modulated by the degree of word-form overlap between languages. Greater translation effects have been found for cognates (i.e., words that share semantic and orthographic and/or phonological representations across languages) than for non-cognates (i.e., words that only share semantic representations). The confluence of overlapping representational levels in cognates provides them with a processing advantage over non-cognate words and gives rise to the cognate facilitation effect: bilinguals recognize, read, produce and translate cognates faster and more accurately than non-cognates (e.g., Caramazza \& Brones, 1979; Cristoffanini, Kirsner, \& Milech, 
1986; De Groot, Borgwaldt, Bos, \& Van den Eijnden, 2002; Dijkstra, Van Jaarsveld, \& Ten Brinke, 1998; Duñabeitia, Perea, \& Carreiras, 2010; Lemhöfer \& Dijkstra, 2004; Lemhöfer, Dijkstra, \& Michel, 2004; van Heuven, Dijkstra, \& Grainger, 1998; see Boada, Sánchez-Casas, Gavilán, García-Albea, \& Tokowicz, 2013, for a review). While the precise mechanisms driving the cognate effects are still being debated, they are typically thought to arise from the convergent triggering of language-shared orthographic, phonological and semantic activation for cognate words. Following the interpretation of connectionist models (e.g., Dijkstra \& Van Heuven, 1998, 2002), the cognate effects may result from the combination of bottom-up and top-down activation, so that "as a consequence of orthographic and semantic overlap, more semantic activation will arise for cognates than for non-cognates", and "the two cognate readings together may induce more global activation in the lexicon than other similar words (such as neighbors) do" (Dijkstra, Miwa, Brummelhuis, Sappelli, \& Baayen, 2010, p. 299). This way, a SpanishEnglish bilingual would access an English word like detective significantly faster than a word like beach due to the greater overlap at different levels (sub-lexical and lexico-semantic) of the former word with its corresponding Spanish translation equivalent (detective-detective vs. playabeach).

Interestingly, the degree of orthographic overlap that cognates share across languages largely determines the size of the cognate facilitation effect. It has been found that orthographically identical cognates (e.g., the Spanish-English example detective) are processed faster than near-identical cognates (e.g., the Spanish-English cognate pairs evidencia-evidence; see Dijkstra, van Heuven, \& Grainger, 1999; Dijkstra et al., 2010; Lemhöfer \& Dijkstra, 2004; Lemhöfer et al., 2004; Van Assche, Duyck, Hartsuiker, \& Diependaele, 2009). According to localist connectionist models of bilingual lexical access (e.g., BIA / BIA+ models; see Dijkstra \& 
Van Heuven, 2002), an increase in cross-linguistic similarity of translation equivalents yields higher levels of activation for the two words in the lexicon, which leads to a modulation of cognate effects as a function of the degree of orthographic overlap. Furthermore, and critically for the purposes of the current study, Bultena, Dijkstra, \& Van Hell (2014) showed that the magnitude of the cognate facilitation effect when reading in a second language decreases as a function of increased L2 proficiency. Nonetheless, and despite the wide range of factors shown to modulate the cognate facilitation effect, what still remains to be explored is the sole influence of reading experience (and not proficiency in a given language) on the cognate facilitation effects, and the current cross-sectional study endeavors to do so by investigating how sensitive bilingual developing readers of different ages are to cognates and non-cognates. To date, the majority of studies exploring cross-language similarity have predominantly tested young adult participants (e.g., all the aforementioned studies) and little is known about the way in which reading expertise modulates bilingual visual word recognition and about the developmental changes that underlie bilingual word comprehension.

Literacy acquisition and consolidation during elementary school has been shown to generate critical changes in the organization of the orthographic lexicon of novice readers. At the beginning stages of reading development, lexical competition between neighboring orthographic representations is enhanced as compared to later stages in which reading skills are consolidated and the structure of the mental lexicon is better established (e.g., Castles, Davis, \& Forster, 2003; Duñabeitia \& Vidal-Abarca, 2008; Laxon, Coltheart, \& Keating, 1988; Perea \& Estévez, 2008). It has been suggested that lexical competition among orthographically similar word forms decreases as an inverse function of reading expertise (see Acha \& Perea, 2008, for review), and as a function of the development of top-down regulatory connections from the language nodes 
and of lateral inhibitory connections (see Grainger et al., 2010, for review of theoretical models $)^{1}$. Considering that orthographic similarity is one of the key factors responsible for the cognate effects, and that younger children are more sensitive than older individuals to orthographic overlap among competing lexical forms, our guiding hypothesis in the current study is that the processing of translation equivalents with different degrees of orthographic overlap in the early stages of life (e.g., during childhood and early adolescence) will markedly change over the course of reading development. While most of the studies testing this hypothesis have focused on between-word competition effects in monolingual children, the present study explored highly proficient bilingual children tested with words from their two lexicons as a window to uncovering developmental changes in the organization of the bilingual lexicon.

Bilingual lexical processing necessarily requires language control mechanisms (e.g., Costa, Santesteban, \& Caño, 2005; Green, 1998), and these mechanisms are largely based on skills related to interference suppression and inhibitory control that develop during childhood and early adolescence (e.g., Antón et al., 2014; Rueda et al., 2004; see Diamond, 2013, for review). While it is unclear whether or not bilingual and monolingual children differ in executive functioning and domain-general inhibitory capacities (cf. Duñabeitia et al., 2014), the necessity of bilingual readers to efficiently organize the words from two languages in lexico-semantic memory is uncontroversial. However, little is known with regard to the specific manner in which the bilingual (orthographic) lexicon is created and even less is known about the developmental

\footnotetext{
${ }^{1}$ Language nodes were assumed to play a key role at the word identification (lexical) level in the BIA model, limiting cross-language interference via top-down inhibitory control (Dijkstra \& Van Heuven, 1998). In contrast, in its latest version (BIA+) they were assumed to have a representational status, providing information regarding language membership as a function of ortho-phonological information, and regulating the interference caused by the non-target language at a post-lexical stage (Dijkstra \& Van Heuven, 2002). Even though the role of language nodes was not fully determined in the BIA-d model (Grainger et al., 2010), they were conceptualized in line with the original proposal, exerting top-down inhibition from the L2 word forms to the L1 translation equivalents, and this inhibitory control was assumed to develop as a function of increased proficiency in the L2.
} 
changes that arise during the course of bilingual reading consolidation. As we will review below, to date, the number of studies testing this issue is very limited, and in most cases restricted to children who are L2 learners.

A promising way to explore bilingual lexical organization, development and competition effects is to investigate the changes in the processing of words with varying degrees of orthographic similarity across languages in children (e.g., cognate words such as the SpanishEnglish word pair guitarra-guitar). In their seminal study on this topic, Brenders, van Hell and Dijkstra (2011) conducted a series of lexical decision experiments testing different groups of Dutch children who were in the process of acquiring English as a second language. Specifically, in two cross-sectional experiments they tested $5^{\text {th }}$ graders (mean age of 10.5 years), $7^{\text {th }}$ graders (mean age of 12.6 years) and $9^{\text {th }}$ graders (mean age of 14.3 years) in a series of lexical decision tasks including cognates and control words. Their results showed that the cognate effects (shorter RTs and lower error rates for cognates than for non-cognates) were present in all groups when responding to L2 words (Experiment 1), whereas it vanished when responding to L1 words (Experiment 2). Interestingly, there were no statistical differences between the magnitudes of the cognate effects across groups in the L2 lexical decision task, in spite of a numerical trend suggesting somewhat larger cognate effects for the younger group (52ms, $10 \mathrm{~ms}$ and $25 \mathrm{~ms}$, respectively). In a related study, Poarch and van Hell (2012) explored the cognate facilitation effects in a series of language production tasks (picture naming) with multilingual children and adults, following preceding research (cf. Hoshino \& Kroll, 2008). In a first experiment, they tested German children (ages ranging between 5 and 8 years) who were immersed in an Englishspeaking academic environment and who were relatively proficient in English, and demonstrated the presence of robust cognate effects in an English picture naming task (but not in their L1, 
German). In a subsequent experiment exclusively testing more proficient yet unbalanced bilinguals from the same cohort, they showed that the presence of cognate effects also extended to the L1, even though the magnitude of the effect was still larger in the L2-naming condition. When these results were compared to those obtained from a bilingual adult sample, Poarch and van Hell observed that the magnitude of the cognate effects was two times larger in children than in adults, both in their L1 and in their L2 (66ms vs. 38ms, and 197ms vs. $102 \mathrm{~ms}$, respectively). This result was accompanied by a general difference in response latencies between children and adults, showing that children took more time to respond than adults.

Based on the aforementioned results suggesting a developmental change in the processing of cognates as a function of reading expertise in bilinguals (e.g., the numerical differences observed by Brenders et al., 2011, with L2 learners in their lexical decision experiments and those reported by Poarch \& van Hell, 2012, with highly proficient bilinguals in their picture naming tasks), in the current study we tested Spanish-Basque balanced bilingual children of different ages in two explicit translation recognition tasks including words with different degrees of cross-language similarity. We tested a large group $(n=100)$ of bilingual participants of different ages using a large set of translation equivalents, while measuring the influence of the cognate rate of the translations on their performance. We used a modified version of the traditional translation recognition task (see Prior, Kroll, \& MacWhinney, 2012, for review), in which a target word in one language was followed by two words in the other language, out of which only one was the target's translation equivalent that the participants were asked to identify.

Following preceding evidence, some predictions could be made with regard to how participants would perform in these translation recognition tasks. First, it was expected that older 
participants would perform better (namely, exhibit shorter response latencies) than younger participants due to their greater exposure to print. Second, considering preceding studies on bilingual word recognition and translation processing, a general effect of cognate status (namely, a modulation of the translation recognition processes as a function of the orthographic overlap between word forms across languages) was also expected in both language directions and for all participants. Finally, bearing in mind the amount of orthographic information cognates carry (to which novice readers are predicted to be especially responsive), larger cognate effects were expected for younger than older participants.

\section{Experiment}

\subsection{Methods}

2.1.1. Participants. One hundred Spanish-Basque bilingual children and adolescents (68 females) were recruited from a bilingual school in the Basque Country. These children had an age range between 8 and 15 years (mean age $=11.51$ years, $S D=2.21$ ). The distribution of participants according to their age (in years) is presented in Figure 1. None of the participants had previously been diagnosed with any neurocognitive disorder or learning disability. In order to preserve the homogeneity across the different age groups, we made sure that all the participants were born and raised in the Basque Country, and that their parents were also originally from the Basque Country. All participants were native speakers of Spanish and Basque, and they were exposed to the two languages from birth at home. Besides, all participants had been attending the same bilingual school from the first grade of elementary school onwards. 
All participants had daily exposure to Basque and Spanish as vehicular languages (linguae francae) during tuition, and all were perfectly fluent in both languages. As already shown in several scientific reports, pupils attending Spanish-Basque bilingual schools in the Basque Country, where both languages are used as the languages of instruction, are highly proficient in both languages (see Antón et al., 2014; Duñabeitia et al., 2014). According to the legal requirements, schools in the Basque Country following a bilingual instruction method (called the B model) require that teachers switch from one language to the other as they switch academic subjects, ensuring a similar distribution of the two languages across subjects and school time (roughly 50\% in each language). This way, Basque children attending bilingual schools are actively exposed to the two languages on a daily basis during schooling. All the participants' parents or legal guardians signed informed consent forms before the experiment and were appropriately informed regarding the basic procedure of the experiment, according to the ethical commitments established by the BCBL Scientific Committee and by the BCBL Ethics Committee that approved the experiment.

2.1.2. Materials. For the Spanish-to-Basque translation direction, 700 Spanish words were selected as references, taken from B-Pal (Davis \& Perea, 2005). These words were part of a translation database containing 2100 Spanish and Basque word pairs rated for the quality of translation, age of acquisition in each of the languages and concreteness by a group of native Basque-Spanish bilingual adults (Duñabeitia, Casaponsa, Dimitropoulou, Martí, Larraza, \& Carreiras, in preparation). The mean length of these Spanish words was 7.67 characters $(\mathrm{SD}=2.14)$, the mean word frequency was 45.26 appearances per million words $(\mathrm{SD}=79.92)$, the mean AoA was $3.2(\mathrm{SD}=0.58)$ on a scale from 1 to 5 where higher values corresponded to words 
acquired later in life, the mean number of orthographic neighbors was $1.43(\mathrm{SD}=2.65)$ and the mean concreteness was $4(\mathrm{SD}=0.86)$ on a scale from 1 to 7 where higher values corresponded to very concrete items. Each of these 700 Spanish reference words was then paired with two different Basque words. One of the Basque words corresponded to the effective translation of the Spanish word (e.g., the Spanish word salud (health) was paired with its corresponding translation equivalent in Basque, osasun). The mean length of these Basque words was 7.59 characters $(\mathrm{SD}=2.10)$, the mean word frequency taken from E-Hitz; (Perea, Urkia, Davis, Agirre, Laseka, \& Carreiras, 2006) was 57.32 appearances per million words $(\mathrm{SD}=218.93)$, the mean AoA was 3.26 $(\mathrm{SD}=0.51)$, the mean number of orthographic neighbors was $1.26(\mathrm{SD}=2.16)$ and the mean concreteness was $4.03(\mathrm{SD}=0.84)$. These translation equivalents were rated as correctly matching translations according to the 1-to-7 scale used in the translation database where 7 corresponded to a perfect translation (mean=6.65, $\mathrm{SD}=0.19$ ). Critically for the purposes of the present study, the cognate status of these translation equivalents was calculated following the length-corrected version of the orthographic Levenshtein distance between Spanish and Basque, ranging from 0 (non-cognates; e.g., febrero and otsail, the Spanish and Basque words for February, respectively) to 1 (full cognates; e.g., maleta, the Spanish and Basque word for suitcase; see Casaponsa, Antón, Pérez, \& Duñabeitia, 2015; Duñabeitia, Dimitropoulou, Morris, \& Diependaele, 2013; Schepens, Dijkstra, \& Grootjen, 2011). Given the extremely high correspondence between the Spanish and Basque phonemes and considering that all the Basque letters are also present in the Spanish alphabet, we focused exclusively on the orthographic Levenshtein distance. The cognate status ranged from 0 to 1 , and the mean cognate rate was 0.46 $(\mathrm{SD}=0.36)$. The distribution of items according to the length-corrected Levenshtein distance is presented in Figure 1. In order to associate each Spanish reference with an unrelated Basque 
word, the real Basque translations were rotated across trials and paired with mismatching Spanish references. Care was taken so that the unrelated Spanish-Basque pairs did not overlap in either orthography or semantics (e.g., the Spanish word salud (health) was paired with the Basque word autobus (bus)). For the Basque-to-Spanish translation direction task, the same 700 Basque words that were previously selected as targets were now used as references (e.g., osasun (health)). These Basque references were paired with their corresponding Spanish translations (e.g., salud), or with an orthographically and semantically unrelated Spanish word created by rotating the related items (e.g., autobús (bus)). In order to maintain homogeneity across the two translation directions, the Spanish and Basque unrelated words used in each trial were also translation equivalents across directions (e.g., autobus and autobús).

$$
<\text { Insert Figure } 1 \text { here }>
$$

2.1.3. Procedure. All the participants completed both tasks (i.e., translation matching from Spanish to Basque and translation matching from Basque to Spanish) in two different experimental sessions that took place in two different days with at least a three-day lag between them and in a counterbalanced order across participants. We explicitly counterbalanced the order of the tasks across participants and set a delay between sessions in order to avoid the presence of cross-language repetition priming effects, which have been previously reported in tasks that require conceptual processing when the study and test phase take place in the same session (see Zeelenberg \& Pecher, 2003). The items were presented using the Experiment Builder software on a CRT screen (positioned approximately $70 \mathrm{~cm}$ in front of the participants) that was linked to a PC, and data collection associated with button presses was collected with a response box (Empirisoft DirectIN High Speed Button-Box). Data collection was always carried out individually on the school premises during the teaching hours. In each experimental session, 
participants were informed that they were going to be presented with a series of words corresponding to the reference language (Spanish or Basque, depending on the translation direction) presented in the center of the screen, followed by two words in a different language presented on the left and right sides of the screen. They were instructed to press, as quickly and accurately as possible, one out of two buttons on the response box to indicate which of the two target words corresponded to the exact translation of the reference word (the leftmost or the rightmost button, depending on the location of the correct translation on the screen). Across trials, half of the correct translations for each reference appeared on the right of the screen, and the other half appeared on the left side. Each trial started with the presentation of a mask (e.g., \#\#\#\#\#) for 500ms located in the exact place were the reference would appear. Then the corresponding word was presented in uppercase Courier New font for 1000ms. Finally, the two target words were presented in lowercase letters until a participant responded or for a maximum of $5000 \mathrm{~ms}$ (see Figure 2). After each trial, feedback about the accuracy was provided for $500 \mathrm{~ms}$ in the center of the screen (-) for correct responses and $: *$ for incorrect responses). The order of trial presentation was randomized across participants, and there were 6 small breaks during the experiment. Prior to the experimental trials, each participant was presented with a short practice consisting of 20 items (10 requiring a left response and 10 requiring a right response). All interactions with the participants and the experimental instructions were in the language corresponding to the references. Each experimental session lasted for around 50 minutes.

$$
<\text { Insert Figure } 2 \text { here }>
$$

\subsection{Results}


Correct RTs for target words were analyzed with linear mixed effects (lme) models as implemented in the lme4 package (Bates, Maechler, Bolker, \& Walker, 2014) in $R$ (R CoreTeam, 2013). Significance p-values and Type III F-statistics for main effects and interactions were calculated using Satterthwaite approximations to degrees of freedom as implemented in the lmerTest package (Kuznetsova, Brockhoff, \& Christensen, 2014). Timeouts (Basque targets: $.59 \%$; Spanish targets: .52\%), errors (Basque targets: 7.72\%; Spanish targets: 9.10\%), and RTs shorter than $300 \mathrm{~ms}$ (Basque targets: .24\%; Spanish targets: .41\%) were excluded from the analysis. For each translation direction, latencies shorter than Q1-2.5*IQR and longer than $\mathrm{Q} 3+2.5 * \mathrm{IQR}$ for each participant (Basque targets: 1.78\%; Spanish targets: 1.94\%) and item (Basque targets: 1.80\%; Spanish target: 1.86\%) were also discarded. This resulted in a dataset of 123,076 data points. Transformed RTs, either by the inverse-transform (-1000/RT) or logarithmic scale attenuated the skew in their distribution just for the oldest participants. Therefore, in order to avoid any age-dependent bias in the distribution of the RTs in the analysis, RTs were entered into the model without any transformation.

We first investigated the presence of a significant interaction between the continuous predictor Cognate Rate and Age, and the categorical factor Translation Direction (i.e., Spanishto-Basque and Basque-to-Spanish) with subjects and items as crossed random factors (e.g., Baayen, 2008; Baayen, Davidson, \& Bates, 2008). Apart from the experimental conditions, we also considered three other control variables that might affect decision latencies along the experimental session, as shown in previous studies (e.g., Diependaele, Duñabeitia, Morris, \& Keuleers, 2011; Mulder, Dijkstra, Schreuder, \& Baayen, 2014, among others). Thus, reaction times to the previous trial (Previous Response), Trial Order, and Session Order were considered as predictors. The maximal-order interaction of the within-unit predictors of interest were 
included as random slopes (see Barr et al., 2013). The random-effect structure of the final model consisted of random intercepts for Item ( $\mathrm{SD}=145)$, and Subject $(\mathrm{SD}=206)$, by-subject random slopes for the interaction of Cognate Rate with Translation Direction (Basque targets: SD=160; Spanish targets: $\mathrm{SD}=162)$, and by-item random slopes for $A g e(\mathrm{SD}=21)$. Due to the differences in scale of our predictors resulting in a very large eigen value in the model, the predictor Age was centered for its inclusion in the final model. The standard deviation of the residual was 339 .

$<$ Insert Tables 1 and 2 here $>$

The F-statistics associated with the main effects and interactions resulting from the model are presented in Table 1, and Table 2 summarizes the coefficients along with standard errors and t-values. Results from the model showed a significant inverse relation between reaction times and Age, showing that response latencies decreased as age increased. The main effect of Cognate Rate was significant, showing that response latencies also decreased as the cognate status of words increased (i.e., translation equivalents with large orthographic overlap across languages yielded shorter response latencies). The main effect of Translation Direction was significant, showing that participants responded faster when targets were presented in Spanish than when they were presented in Basque. This factor significantly interacted with Age, showing that the decrease in reaction times as Age increased was milder for Spanish targets $(\mathrm{b}=-78, \mathrm{SD}=10, \mathrm{t}=$ 8.22, $\mathrm{p}<.001)$ than for Basque targets $(\mathrm{b}=-87, \mathrm{SD}=10, \mathrm{t}=-9.14, \mathrm{p}<.001$; see Figure 3$)$. Interestingly for the purposes of the current study, the interaction between Cognate Rate and Age resulted significant in the model and did not significantly differ between both translation directions (see Table 1). As can be seen in Figure 3 ( $b$ and $c$ ), there was a marked decrease in the reaction times as the orthographic overlap between languages increased and, critically, the magnitude of these cognate effects diminished with age. In other words, results showed that the 
magnitude of the cognate effects significantly decreased as an inverse function of age in both translation directions (Basque targets: $b=41, \mathrm{SD}=8, \mathrm{t}=5.30, \mathrm{p}<.001$; Spanish targets: $\mathrm{b}=36$, $\mathrm{SD}=8, \mathrm{t}=4.51, \mathrm{p}<.001)$, being maximal at initial stages of reading development and progressively diminishing with age.

$<$ Insert Figure 3 here $>$

Recent research has suggested that the classic cognate effects may depend on the presence of identical (fully overlapping) cognates within the list of stimuli (see Comesaña et al., 2015; see also Comesaña et al., 2012). Given that the current experiment also included identical cognates, we decided to further explore whether the presence of such translation equivalents may have modulated the results by reanalyzing the data while excluding fully overlapping cognates from the list. Tentatively, it could be argued that, in the context of the current experiment, translation recognition of full cognate words (translation equivalents with cognate rates of 1) could be guided by a mere repetition-match strategy, thus boosting the presence of a cognate effect. To ensure that the results of the model were not biased by this factor, the same model was refitted by excluding fully overlapping cognate translations from the set (86 items). Importantly, the analysis yielded a similar pattern of results. The three main effects remained significant (Cognate Rate: $\mathrm{F}=145.25, \mathrm{p}<.001 ;$ Age: $\mathrm{F}=43.83, \mathrm{p}<.001$, Translation Direction: $\mathrm{F}=18.93$, $\mathrm{p}<.001)$. As in the analysis with the whole set of items, in this new analysis the interaction between Age and Translation Direction was also found $(\mathrm{F}=6.79, \mathrm{p}<.01)$ and, critically, the interaction between Cognate Rate and Age was also replicated ( $\mathrm{F}=14.95, \mathrm{p}<.001)$, showing that response latencies diminished as the orthographic overlap between translations increased, and that these cognate effects diminished with Age in both translation directions (Basque targets: $b=$ $40, \mathrm{SD}=9, \mathrm{t}=4.72, \mathrm{p}<.001$; Spanish targets: $\mathrm{b}=34, \mathrm{SD}=9, \mathrm{t}=3.84, \mathrm{p}<.001)$. Furthermore, the 
magnitude of these effects did not statistically differ between translation directions $(\mathrm{F}=.65$, $\mathrm{p}=.52)$.

Previous literature has shown that overall speed differences across participants can lead to spurious over-additive interactions (see Faust, Balota, Spieler, \& Ferraro, 1999; Ziegler, Bertrand, Lété, \& Grainger, 2014, among others). Not surprisingly, the participants tested in the current study showed an overall effect of Age (i.e., shorter reaction times for the older participants), and this could be thought to contribute to the greater Cognate Rate effects (i.e., the more marked slopes) for the younger participants. To address this critical issue, we standardized the data for each participant using z-scores. Thus, data were transformed so that each participant had a mean of 0 and a standard deviation of 1 in each translation direction. We then reanalyzed these data following the same structure used in the main analysis in order to explore whether the interaction between Age and Cognate Rate remained significant with the standardized scores. Results are summarized in Tables 3 and 4. Results confirmed the significant inverse relationship between Cognate Rate and Age, as shown in the analysis on the non-standardized RTs. The interaction between these two continuous predictors of interest was significant, showing that the slope of Cognate Rate was more pronounced for older than for younger participants (i.e., greater cognate effects for younger children; see Figure 4). Hence, the results from the analysis on the transformed data replicated the initial analysis, showing that as the age increased, the magnitude of the cognate effects decreased.

$$
\begin{gathered}
<\text { Insert Tables } 3 \text { and } 4 \text { here }> \\
<\text { Insert Figure } 4 \text { here }>
\end{gathered}
$$




\section{General Discussion}

The main goal of the present study was to investigate how the degree of orthographic overlap between translation equivalents influenced bilingual word recognition processes at different stages of reading development, in order to better understand how bilingual lexical organization changes over the course of bilingual reading consolidation. We tested 100 SpanishBasque bilinguals of different ages in two translation recognition tasks (Spanish-to-Basque translation direction and Basque-to-Spanish translation direction). Results showed a general modulation of reading performance as a function of reading development. The younger the participants were, the slower the translation recognition process. In addition, and more importantly for the focus of this study, the results showed that the degree of orthographic overlap between translation equivalents helped bilingual translation recognition and, critically, that this cognate effect progressively diminished with age.

Results showed that the response latencies to translation equivalents decreased with age. Hence, we observed a general modulation of bilinguals' ability to recognize translation equivalents that is related to their general reading skills and to their stage of reading development. These general results from the translation recognition task are in line with evidence from monolingual samples showing that general reading skills get progressively tuned and consolidated during the transition from childhood to adolescence (see Grainger et al., 2012). It is well known that at the early stages of reading development several factors play an important role and affect the variability observed in children's proficiency while reading (e.g., general cognitive development, working memory capacity, general intelligence, exposure to print at home, etc.) and that this variability tends to diminish by the end of elementary education (Coombe, 2010; Ellis, 1996; Folse, 2004; Nation, 1990, 2001, 2006; Papagno \& Vallar, 1995; Service, 1992). 
Critically, response latencies were modulated by the degree of orthographic overlap between translation equivalents, showing that along the continuum of cognate status, cognate words were recognized faster than non-cognate words (see Figure 2). The degree of orthographic overlap between translation equivalents is a critical aiding factor during the bilingual word recognition process, as shown by multiple studies demonstrating facilitation effects for cognates over non-cognates using different tasks and paradigms (e.g., Boada et al., 2013; De Groot \& Comijs, 1995; De Groot, Dannenburg, \& Van Hell, 1994; Duñabeitia, Perea, \& Carreiras, 2010). In the current study we replicated this cognate advantage in the translation recognition task using a continuous measure of the degree of cross-linguistic orthographic overlap (based on the length002Dcorrected Levenshtein distance; see Casaponsa et al., 2015; Duñabeitia et al., 2013; Schepens et al., 2011; see also Prior, Kroll, \& MacWhinney, 2013, for an alternative approach). The present experiment adds to that evidence by showing a general cognate facilitation effect that increases as a direct function of the degree of orthographic overlap between translation equivalents. Participants' response latencies decreased as the orthographic similarity between the translation equivalents increased.

Even though all participants had already acquired basic reading skills and were proficient in both of their languages, there was a clear-cut gradation of the degree of automation and consolidation of the bilingual visual word recognition processes as a function of age. In this line, results showed a significantly better performance in the translation recognition task for older than for younger participants (i.e., shorter response latencies). Moreover, this pattern was replicated in both language translation directions (Spanish-to-Basque and Basque-to-Spanish). While the effect of age was significantly stronger in the Spanish-to-Basque translation direction than in the Basque-to-Spanish translation direction, the magnitude of the effect of cognate rate 
was not modulated by the translation direction. In other words, the direction of the translation recognition process had little impact on the observed decreasing pattern of cognate effects across age. This is not such a surprising finding, considering that in simultaneous balanced bilinguals a straightforward L1-L2 division cannot be made at the level of proficiency, given that they are equally proficient in both languages. Their languages are in that sense better characterized as multiple L1s (see Duñabeitia, Dimitropoulou, Uribe-Etxebarria, Laka, \& Carreiras, 2010; Duñabeitia, Perea, \& Carreiras, 2010; Perea, Duñabeitia, \& Carreiras, 2008).

More importantly, the effect of orthographic overlap between translation equivalents was modulated by the age of the bilingual participants. The younger the children were, the greater facilitation effects along the cognate status continuum were found, and these results were replicated in both translation directions. Furthermore, an analysis of the data using z-scores in order to control for the fact that younger children were much slower on the task than older participants showed that these results did not depend on the general speed of response. These results suggest that less proficient readers are more responsive to and reliant on cross-language orthographic overlapping features than more experienced readers, and that they benefit more from these types of cues during bilingual word recognition. Hence, these results demonstrate that cognate effects are not only maximal at lower levels of L2 proficiency (see Bultena et al., 2014), but also at lower levels of reading skills, even when the participants tested are highly proficient in the two languages at test. (Note in this regard that all bilinguals tested in the current study attended a bilingual school and had acquired reading in both languages simultaneously). This is in line with the evidence suggesting that the orthographic characteristics of words play an important role during word processing in young children (e.g., Davis, Castles, \& Iakovidis, 1998; 
Grainger \& Ziegler, 2011; Grainger et al., 2012; Ziegler et al., 2014), and extends this finding to bilingual word processing.

The present results complement a recent observation from a word production study by Poarch and van Hell (2012) testing bilingual children's sensitivity to the cognate status of words by extending those results to the visual word recognition domain suggesting that the cognate effects diminish as an inverse function of age in translation recognition tasks. The highly proficient non-balanced bilingual samples tested by Poarch and van Hell in their picture naming study displayed significant cognate effects in both their L1 and L2, and critically, the magnitude of the cognate effects was found to be much larger (specifically, two times larger) for children with a mean age of 7.28 years than for young adults with a mean age of 24.4 years. (Note, however, that Poarch and van Hell did not directly statistically compare the magnitude of the cognate effects across the ages). Hence, the present study extends those findings by demonstrating that sensitivity to cross-language orthographic overlap diminishes with age in highly proficient bilinguals in a language comprehension task. In a related vein, it is worth noting that in a bilingual language comprehension study using the lexical decision task with young Dutch learners of English, Brenders et al. (2011) also showed significant cognate effects in the L2 (but not in the L1) for three groups of relatively proficient non-balanced bilingual children (mean ages of 10.5, 12.6 and 14.3 years). However, and in partial contrast to the present results, the interaction between cognate status and group did not result significant in the study by Brenders et al., thus suggesting that the cognate effects remained relatively constant across ages. Nonetheless, there are sufficient reasons to believe that the present results and those reported by Brenders et al. are not at odds. Leaving aside the differences in the tasks at stake (lexical decision vs. translation recognition), in the present study we tested highly proficient bilingual 
children from different ages immersed in a bilingual community and who were attending a bilingual school where the two active languages (Spanish and Basque) are used a similar amount of time, while Brenders and colleagues tested a completely different group of bilinguals with much more limited exposure to their L2 (i.e., they were native Dutch children living in monolingual Dutch families, and they had been exposed to English as a second language only in the academic context). Besides, the amount of exposure to English as a second language of the children tested in the Brenders et al. study largely varied across groups (i.e., 5 months for the younger group, and 3 and 5 years for the two older groups, respectively), thus making a direct comparison between the two cohorts difficult.

Which are the mechanisms responsible for the developmental changes in the cognate effects observed in the current study? The first approach interpreting the finding of the cognate effects' diminution as a function of age relies on the different reading skills (i.e., reading expertise) of the participants tested. Our bilingual children's two languages are essentially transparent, in that there are relatively unambiguous grapheme-phoneme correspondences that are shared across Basque and Spanish. Relatedly, developmental studies on reading acquisition and consolidation in multiple languages suggest that inexperienced readers of orthographically consistent languages strongly rely on recoding strategies based on small ortho-phonological units (i.e., the psycholinguistic grain size theory; see Ziegler \& Goswami, 2005, 2006), and that larger size units are used once reading has been consolidated. Hence, according to these premises, we tentatively interpret the larger cognate effects observed during translation recognition for younger rather than for older participants as a consequence of the greater reliance of the former on sub-lexical units, which in the case of cognate translations are shared across languages, thus speeding up the recognition process. The shared (language-independent) nature of sub-lexical 
orthographic and phonological units that we assume here is in line with preceding studies on biscriptal readers suggesting that graphemes and phonemes that are identical across languages or scripts (with identical spelling-sound correspondences) are integrated in a single orthographic lexicon (see Dimitropoulou, Duñabeitia, \& Carreiras, 2011c; Havelka \& Rastle, 2005). In contrast, and as suggested by Ziegler and Goswami (2006), consolidation of reading skills involves a lesser degree of reliance on sub-lexical cues during visual word identification, and this could partially explain why older bilinguals exhibit reduced cognate effects (see also Acha \& Perea, 2008, and Kohnert, 2010). In a related vein, studies exploring similarities and differences in the magnitude of cognate effects between young and older bilingual adults have also suggested a critical modulation of cross-language interactions as a function of age. It has been proposed that "lexical access in older bilinguals may be detrimentally affected by the form similarity of cognate translations" (Siyambalapitiya, Chenery, \& Copland, 2009, p. 548), in line with previous research demonstrating that the reliance on form similarity between competing lexical forms dramatically changes as a function of age (see Logan \& Balota, 2003), so that the cognate effects can vanish (and even go in the opposite direction) in the elderly.

Developmental models of bilingual lexical access have proposed that lateral inhibition processes that are responsible for the management of cross-language interactions are strengthened as a function of experience (see BIA-d model, Grainger et al., 2010). Following the rationale of the Bilingual Interactive-Activation model (BIA; Grainger \& Dijkstra, 1992; van Heuven, Dijkstra, \& Grainger, 1998), the BIA-d model assumes that at the initial stages of visual word recognition, lexical access is non-selective, and language-specific representations are accessed "due to the conjoint operation of top-down and lateral inhibitory mechanisms" (Grainger et al., 2010, p. 271). According to this model, the excitatory connections between 
translation equivalents are initially enhanced in the presence of orthographic overlap (thus explaining the cognate facilitation effect), but it is predicted that these excitatory connections decay rapidly as proficiency increases, as an inverse function of the development of top-down regulatory mechanisms from the corresponding language nodes and of the development of lateral inhibitory connections between formally overlapping words in the two languages. Hence, the BIA-d model suggests that the strength of the connections between translation equivalents, and especially between orthographically similar translations, is reduced due to the development of lateral and top-down inhibitory connections (Grainger et al., 2010; see also Casaponsa et al., 2015). Hence, one could interpret the current findings based on the different interference suppression skills of younger and older bilingual children, as suggested by the BIA-d model. While it is true that bilingual children master interference suppression in order to deal with the words from one of their two languages with minimal intrusions from the other language (see Martin-Rhee \& Bialystok, 2008, for review), the attentional mechanisms supposedly responsible for such language control are not rigidly set during early childhood as they are in continuous development during infancy (e.g., Antón et al., 2014; Rueda et al., 2004). It could be hypothesized that younger children show greater cross-language similarity effects than older children as a consequence of their still immature language control system (yielding impoverished top-down regulatory activity from the language nodes and lateral inhibitory regulation at the lexical level), which makes them more sensitive to cross-language interference effects (here measured by the cognate status of words). While the current results fit well along the lines sketched in the BIA-d model, we acknowledge that this model was initially intended to account for bilingual lexical access in late learners of a second language. Hence, the future revised versions of this developmental model should also incorporate predictions regarding the way in 
which access to the bilingual lexicon is differently mediated by bottom-up and top-down regulatory factors as a function of age in relatively balanced and simultaneous bilinguals.

Together, these results demonstrate that the consolidation of the bilingual orthographic lexicon follows a developmental trajectory during childhood that is initially governed by a greater reliance on cross-language similarity possibly due to the still immature bilingual language control system of novice readers. Once bilingual reading becomes automatic as a function of increased exposure to print and once the attentional mechanisms responsible for cross-language interference suppression are fully set and developed, bilinguals' sensitivity to competing neighboring orthographic representations decays, leading to the progressive diminishing of the cognate effects observed in the current study. 


\section{References}

Acha, J., \& Perea, M. (2008). The effects of length and transposed-letter similarity in lexical decision: Evidence with beginning, intermediate, and adult readers. British Journal of Psychology, 99, 245-264.

Antón, E., Duñabeitia, J. A., Estévez, A., Hernández, J. A., Castillo, A., Fuentes, L. J., Davidson, D. J., \& Carreiras, M. (2014). Is there a bilingual advantage in the ANT task? Evidence from children. Frontiers in Psychology, 5:398.

Baayen, R. H. (2008). Analyzing Linguistic Data: A Practical Introduction to Statistics Using R. Cambridge University Press. New York.

Baayen, R. H., Davidson, D. J., \& Bates, D. M. (2008). Mixed-effects modeling with crossed random effects for subjects and items. Journal of Memory and Language, 59(4), 390412.

Barr, D. J., Levy, R., Scheepers, C., \& Tily, H. J. (2013). Random-effects structure for confirmatory hypothesis testing: Keep it maximal. Journal of Memory and Language, 68, 255278.

Basnight-Brown, D. M., \& Altarriba, J. (2007). Differences in semantic and translation priming across languages: the role of language direction and language dominance. Memory and Cognition, 35, 953-965.

Bates, D., Maechler, M., Bolker B., \& Walker, S. (2014). lme4: Linear mixed-effects models using Eigen and S4. R package version 1.1-7, [Computer software manual]. Available from http://CRAN.R-project.org/package=lme4. 
Boada, R., Sánchez-Casas, R., Gavilán, J. M., García-Albea, J. E., \& Tokowicz, N. (2013). Effect of multiple translations and cognate status on translation recognition performance of balanced bilinguals. Bilingualism: Language and Cognition, 16, 183-197.

Brenders, P., Van Hell, J. G., \& Dijkstra, T. (2011). Word recognition in child second language learners: Evidence from cognates and false friends. Journal of Experimental Child Psychology, 109, 383-396.

Bultena, S., Dijkstra, T., \& Van Hell, J. G. (2014). Cognate effects in sentence context depend on word class, L2 proficiency, and task. The Quarterly Journal of Experimental Psychology, 67(6), 1214-1241.

Caramazza, A., \& Brones, I. (1979). Lexical access in bilinguals. Bulletin of the Psychonomic Society, 13, 212-214.

Casaponsa, A., Antón, E., Pérez, A., \& Duñabeitia, J. A. (2015). Foreign language comprehension achievement: insights from the cognate facilitation effect. Frontiers in Psychology, 6:588.

Casaponsa, A., Carreiras, M., \& Duñabeitia, J. A. (2014). Discriminating languages in bilingual contexts: The impact of orthographic markedness. Frontiers in Psychology, 5:424.

Castles, A., Davis, C., \& Forster, K.I. (2003). Word recognition development in children: Insights from masked-priming. In S. Kinoshita \& S. Lupker (Eds.), Masked priming: State of the art (pp. 345-360). Hove, UK: Psychology Press.

Chen, H. C., \& Ng, M. L. (1989). Semantic facilitation and translation priming effects in Chinese-English bilinguals. Memory \& Cognition, 17(4), 454-462. 
Coltheart, M., Rastle, K., Perry, C., Langdon, R., \& Ziegler, J. (2001). The DRC model: A model of visual word recognition and reading aloud. Psychological Review, 108, 204 - 258.

Comesaña, M., Ferré, P., Romero, J., Guasch, M., Soares, A. P., \& García-Chico, T. (2015). Facilitative effect of cognate words vanishes when reducing the orthographic overlap: The role of stimuli list composition. Journal of Experimental Psychology: Learning, Memory, and Cognition, 41(3), 614-635.

Comesaña, M., Sánchez-Casas, R., Soares, A. P., Pinheiro, A. P., Rauber, A., Frade, S., \& Fraga, I. (2012). The interplay of phonology and orthography in visual cognate word recognition: An ERP study. Neuroscience Letters, 529, 75-79.

Coombe, C. (2010). Assessing vocabulary in the language classroom. Kuala Lumpur, Malaysia: the Malaysian English Language Teaching Association.

Costa, A., Santesteban, M., \& Caño, A. (2005). On the facilitatory effects of cognate words in bilingual speech production. Brain and Language, 94, 94-103.

Cristoffanini, P., Kirsner, K., \& Milech, D. (1986). Bilingual lexical representation: The status of Spanish-English cognates. Quarterly Journal of Experimental Psychology, 38A, 367393.

Davis, C. J., \& Perea, M. (2005). BuscaPalabras: A program for deriving orthographic and phonological neighborhood statistics and other psycholinguistic indices in Spanish. Behavior Research Methods, 37, 665-671. 
Davis, C. J., Castles, A., \& Iakovidis, E. (1998). Masked homophone and pseudohomophone priming in children and adults. Language and Cognitive Processes, 13, 625651.

De Groot, A. M. B., \& Comijs, H. (1995). Translation recognition and translation production: Comparing a new and an old tool in the study of bilingualism. Language Learning, 45, 467-509.

De Groot, A. M. B., \& Nas, G. L. J. (1991). Lexical representation of cognates and noncognates in compound bilinguals. Journal of Memory and Language, 30, 90-132.

De Groot, A. M. B., Borgwaldt, S., Bos, M., \& Van den Eijnden, E. (2002). Lexical decision and word naming in bilinguals: Language effects and task effects. Journal of Memory and Language, 47, 91-124.

De Groot, A. M. B., Dannenburg, L., \& Van Hell, J. G. (1994). Forward and backward word translation by bilinguals. Journal of Memory and Language, 33, 600-629.

Diamond, A. (2013). Executive Functions. Annual Review of Psychology, 64, 135-168.

Diependaele, K., Duñabeitia, J. A., Morris, J., \& Keuleers, E. (2011). Fast morphological effects in first and second language word recognition. Journal of Memory and Language, 64, 344-358.

Dijkstra, T., Miwa, K., Brummelhuis, B., Sappeli, M., \& Baayen, R. H. (2010). How cross-language similarity and task demands affect cognate recognition. Journal of Memory and Language, 62, 284-301. 
Dijkstra, A., \& Van Heuven, W. J. B. (1998). The BIA model and bilingual word recognition. In J. Grainger \& A. Jacobs (Eds.), Localist connectionist approaches to human cognition (pp. 189-225). Hillsdale, NJ: Erlbaum.

Dijkstra, A., \& van Heuven, W. J. B. (2002). The architecture of the bilingual word recognition system: From identification to decision. Bilingualism: Language and Cognition, 5, $175-197$.

Dijkstra, T., van Heuven, W. J. B., \& Grainger, J. (1999). Recognition of cognates and interlingual homographs: The neglected role of phonology. Journal of Memory and Language, 41, 496-518.

Dijkstra, T., Van Jaarsveld, H., \& Ten Brinke, S. (1998). Interlingual homograph recognition: Effects of task demands and language intermixing. Bilingualism: Language and Cognition, 1, 51-66.

Dimitropoulou, M., Duñabeitia, J. A., \& Carreiras, M. (2011a). Masked translation priming effects with low proficient bilinguals. Memory and Cognition, 39(2), 260-275.

Dimitropoulou, M., Duñabeitia J. A., \& Carreiras, M. (2011b). Two words, one meaning: evidence of automatic co-activation of translation equivalents. Frontiers in Psychology, 2(188), $1-20$.

Dimitropoulou, M., Duñabeitia, J.A., \& Carreiras, M. (2011c). Transliteration and transcription effects in bi-scriptal readers: The case of Greeklish. Psychonomic Bulletin \& Review, 18(4), 729-735. 
Duñabeitia, J. A., Casaponsa, A., Dimitropoulou, M., Martí, A., Larraza, S., \& Carreiras, M. (In preparation). BaSp: A Basque-Spanish database of translation equivalents.

Duñabeitia, J. A., Dimitropoulou, M., Morris, J., \& Diependaele, K. (2013). The role of form in morphological priming: Evidence from bilinguals. Language and Cognitive Processes, $28,967-987$.

Duñabeitia, J. A., Dimitropoulou, M., Uribe-Etxebarria, O., Laka, I., \& Carreiras, M. (2010). Electrophysiological correlates of the masked translation priming effect with highly proficient simultaneous bilinguals. Brain Research, 1359, 142-154.

Duñabeitia, J. A., Hernández, J. A., Antón, E., Macizo, P., Estévez, A., Fuentes, L. J., \& Carreiras, M. (2014). The inhibitory advantage in bilingual children revisited: myth or reality? Experimental Psychology, 61(3), 234-251.

Duñabeitia, J. A., Perea, M., \& Carreiras, M. (2010). Masked translation priming effects with highly proficient simultaneous bilinguals. Experimental Psychology, 57(2), 98-107.

Duñabeitia, J. A., \& Vidal-Abarca, E. (2008). Children like dense neighborhoods: Orthographic neighborhood density effects in novel readers. The Spanish Journal of Psychology, $11,26-35$.

Duyck, W., \& Warlop, N. (2009). Translation priming between the native language and a second language: new evidence from Dutch-French bilinguals. Experimental Psychology, 56(3), $173-179$. 
Ellis, N. C. (1996). Working memory in the acquisition of vocabulary and syntax: Putting language in good order. The Quarterly Journal of Experimental Psychology: Section A 49: 234250.

Faust, M. E., Balota, D. A., Spieler, D. H., \& Ferraro, F. R. (1999). Individual differences in information-processing rate and amount: Implications for group differences in response latency. Psychological Bulletin, 125, 777-799.

Folse, K. S. (2004). Vocabulary myths: Applying second language research to classroom teaching. Ann Arbor, MI: University of Michigan Press.

Gollan, T. H., Forster, K. I., \& Frost, R. (1997). Translation priming with different scripts: Masked priming with cognates and noncognates in Hebrew-English bilinguals. Journal of Experimental Psychology: Learning, Memory, \& Cognition, 23(5), 1122-1139.

Grainger, J. Midgley, K. J., \& Holcomb, P. J. (2010). Re-thinking the bilingual interactive-activation model from a developmental perspective (BIA-d). In M. Kail and M. Hickman (Eds.), Language Acquisition across linguistic and cognitive systems (pp. 267-284). Philadelphia: John Benjamins.

Grainger, J., \& Dijkstra, T. (1992). On the representation and use of language information in bilinguals. In R. Harris (Ed.), Cognitive processing in bilinguals (pp. 207-220). Amsterdam: Elsevier.

Grainger, J., \& Frenck-Mestre, C. (1998). Masked priming by translation equivalents in bilinguals. Language and Cognitive Processes, 13, 601-623.

Grainger, J., \& Ziegler, J. C. (2011). A dual-route approach to orthographic processing. Frontiers in Psychology, 2, 54. 
Grainger, J., Lété, B., Bertand, D., Dufau, S., \& Ziegler, J. C. (2012). Evidence for multiple routes in learning to read. Cognition, 123, 280-292.

Green, D. W. (1998). Mental control of the bilingual lexico-semantic system. Bilingualism: Language and Cognition, 1, 67-81.

Havelka, J. \& Rastle, K. (2005). The assembly of phonology from print is serial and subject to strategic control: Evidence from Serbian. Journal of Experimental Psychology: Learning, Memory, \& Cognition. 31, 148-158.

Hoshino, N., \& Kroll, J. F. (2008). Cognate effects in picture naming: Does cross language activation survive a change of script? Cognition, 106, 501-511.

Jiang, N., \& Forster, K. I. (2001). Cross-language priming asymmetries in lexical decision and episodic recognition. Journal of Memory and Language, 44(1), 32-51.

Kim, J., \& Davis, C. (2003). Task effects in masked cross-script translation and phonological priming. Journal of Memory and Language, 49, 484-499.

Kohnert, K. (2010). Bilingual children with primary language impairment: issues, evidence and implications for clinical actions. Journal of Communication Disorders, 43, 456473.

Kuznetsova, A., Brockhoff, P. B., \& Christensen, R. H. B. (2014). lmerTest: Tests in Linear Mixed Effects Models. R package version 2.0-20. Available from http://CRAN.Rproject.org/package=lmerTest 
Laxon, V., Coltheart, V., \& Keating, C. (1988). Children find friendly words friendly too: Words with many orthographic neighbours are easier to read and spell. British Journal of Educational Psychology, 58, 103-119.

Lemhöfer, K., \& Dijkstra, T. (2004). Recognizing cognates and interlexical homographs: Effects of code similarity in language specific and generalized lexical decision. Memory and Cognition, 32(4), 533-550.

Lemhöfer, K., Dijkstra, T., \& Michel, M. C. (2004). Three languages, one ECHO: Cognate effects in trilingual word recognition. Language and Cognitive Processes, 19(5), 585611.

Logan, J. M., \& Balota, D. A. (2003). Conscious and unconscious lexical retrieval blocking in younger and older adults. Psychology and Aging, 18, 537-550.

Martin-Rhee M. M., \& Bialystok, E. (2008). The development of two types of inhibitory control in monolingual and bilingual children. Bilingualism: Language and Cognition, 11, 8193.

Mulder, K., Dijkstra, T., Schreuder, R., \& Baayen, R. H. (2014). Effects of primary and secondary morphological family size in monolingual and bilingual word processing. Journal of Memory and Language, 72, 59-84.

Nation, I. S. P. (1990). Teaching and learning vocabulary. New York: Heinle and Heinle.

Nation, I. S. P. (2001). Learning vocabulary in another language. New York: Cambridge University Press. 
Nation, I. S. P. (2006). How large a vocabulary is needed for reading and listening? The Canadian Modern Language Review, 63, 59-82.

Papagno, C., \& Vallar, G. (1995). Short-term memory and vocabulary learning in polyglots. Quarterly Journal of Experimental Psychology, 48A, 98-107.

Perea, M., \& Estévez, A. (2008). Transposed-letter similarity effects in naming pseudowords: Evidence from children and adults. European Journal of Cognitive Psychology, $20,33-46$.

Perea, M., Duñabeitia, J. A., \& Carreiras, M. (2008). Masked associative/semantic priming effects across languages with highly proficient bilinguals. Journal of Memory and Language, 58, 916-930.

Perea, M., Urkia, M., Davis, C. J., Agirre, A., Laseka, E., \& Carreiras, M. (2006). E-Hitz: A word-frequency list and a program for deriving psycholinguistic statistics in an agglutinative language (Basque). Behavior Research Methods, 38, 610-615.

Poarch, G. J. \& Van Hell, J. G. (2012). Cross-language activation in children's speech production: Evidence from second language learners, bilinguals, and trilinguals. Journal of Experimental Child Psychology, 111 (3), 419-438.

Prior, A., Kroll, J. F., \& MacWhinney, B. (2013). Translation ambiguity but not word class predicts translation performance. Bilingualism: Language and Cognition, 16(2), 458-474.

R CoreTeam. (2013). R: A Language and Environment for Statistical Computing [Computer software manual]. Vienna, Austria. Retrieved from: http://www.R-project.org/ (Version 3.0.0). 
Rueda, M. R., Fan, J., McCandliss, B. D., Halparin, J. D., Gruber, D. B., Lercari, L. P., \& Posner, M. I. (2004). Development of attentional networks in childhood. Neuropsychologia, 42(8), 1029-1040.

Schepens, J., Dijkstra, T., \& Grootjen, F. (2011). Distributions of cognates in Europe as based on Levenshtein distance. Bilingualism: Language and Cognition, 15, 157-166.

Schoonbaert, S., Duyck, W., Brysbaert, M., \& Hartsuiker, R. J. (2009). Semantic and translation priming from a first language to a second and back: Making sense of the findings. Memory and Cognition, 37, 569-586.

Schoonbaert, S., Holcomb, P. J., Grainger, J., \& Hartsuiker, R. J. (2010). Testing asymmetries in noncognate translation priming: Evidence from RTs and ERPs. Psychophysiology, 1-8.

Service, E. (1992). Phonology, working memory, \& foreign-language learning. Quarterly Journal of Experimental Psychology, 45A, 21-50.

Siyambalapitiya, S., Chenery, H. J., \& Copland, D. A. (2009). Bilingualism and aging: Reversal of the cognate advantage in older bilingual adults. Applied Psycholinguistics 30(3), $531-554$.

Thierry, G. \& Wu, Y. J. (2007). Brain potentials reveal unconscious translation during foreign language comprehension. Proceedings of the National Academy of Sciences of the USA, 104(30), 12530-12535.

Vaid, J., \& Frenck-Mestre, C. (2002). Do orthographic cues aid language identification? A laterality study with French-English bilinguals. Brain and Language, 82, 47-53. 
Van Assche, E., Duyck, W., Hartsuiker, R. J., \& Diependaele, K. (2009). Does bilingualism change native-language reading? Cognate effects in sentence context. Psychological Science, 20, 923-927.

Van Hell, J. G., \& Tanner, D. (2012). Second language proficiency and cross-language lexical activation. Language Learning, 62,148-171.

van Heuven, W. J. B., Dijkstra T., \& Grainger J. (1998). Orthographic neighborhood effects in bilingual word recognition. Journal of Memory and Language, 39, 458-483.

van Kesteren, R., Dijkstra, T., \& de Smedt, K. (2012). Markedness effects in NorwegianEnglish bilinguals: Task-dependent use of language-specific letters and bigrams. Quarterly Journal of Experimental Psychology, 65(11), 2129-2154.

Williams, J. N. (1994). The relationship between word meanings in the first and second language: Evidence for a common, but restricted, semantic code. European Journal of Cognitive Psychology, 6, 195-220.

Wu, Y. J., \& Thierry, G. (2010). Chinese-English bilinguals reading English hear Chinese. The Journal of Neuroscience, 30(22), 7646-7651.

Zeelenberg, R., \& Pecher, D. (2003). Evidence for long-term cross-language repetition priming in conceptual implicit memory tasks. Journal of Memory and Language, 49, 80-94.

Ziegler, J. C., \& Goswami, U. (2005). Reading acquisition, developmental dyslexia, and skilled reading across languages: a psycholinguistic grain size theory. Psychological Bulletin, 131, 3-29. 
Ziegler, J. C., \& Goswami, U. (2006). Becoming literate in different languages: Similar problems, different solutions. Developmental Science, 9(5), 429-436.

Ziegler, J. C., Bertrand, D., Lété, B., \& Grainger, J. (2014). Orthographic and Phonological Contributions to Reading Development: Tracking Developmental Trajectories Using Masked Priming. Developmental Psychology, 50(4), 1026-1036. 


\section{Tables}

Table 1. Main effects and interactions of the predictors of interest of the full model (Type-3 Ftests using Satterthwaite denominator degrees of freedom approximations)

\begin{tabular}{lcc}
\hline & F-value & p-value \\
\hline Cognate rate & 136.5 & $<.001$ \\
Age & 29.0 & $<.001$ \\
Direction & 19.5 & $<.001$ \\
Cognate rate $\|$ Age & 6.3 & .01 \\
Cognate rate || Direction & 1.0 & .39 \\
Age || Direction & 7.2 & .001 \\
Cognate rate || Age $\|$ Direction & .4 & .51 \\
\hline
\end{tabular}


Table 2. Coefficients of the fixed effects together with standard errors and t-values.

\begin{tabular}{|c|c|c|c|c|}
\hline & Estimate & Std. Error & t-value & \\
\hline (Intercept) & 1145 & 25 & 45.92 & $* * *$ \\
\hline Cognate rate & -418 & 22 & -18.62 & $* * *$ \\
\hline Age & -87 & 10 & -9.14 & $* * *$ \\
\hline Direction & -87 & 13 & -6.70 & $* * *$ \\
\hline Trial order & -.05 & -.01 & -11.24 & $* * *$ \\
\hline Session order & 7 & 20 & .39 & \\
\hline PreviousResponse & .14 & .01 & -56.58 & $* * *$ \\
\hline Cognate rate $\|$ Age & 41 & 7 & 5.30 & $* * *$ \\
\hline Cognate rate $\mid$ Direction & 36 & 28 & 1.29 & \\
\hline Age||Direction & 9 & 2 & 3.71 & $* * *$ \\
\hline Cognate rate $\|$ Age $\mid$ Direction & -6 & 9 & -.66 & \\
\hline
\end{tabular}

Note. All flagged t-values are significant at the $\mathrm{p}<.001$ level.

The reference value for translation direction is Spanish-to-Basque. 
Table 3. Main effects and interactions of the predictors of interest of the full model for the transformed data using z-scores (Type-III F-tests using Satterthwaite denominator degrees of freedom approximations).

\begin{tabular}{lcc}
\hline & F-value & p-value \\
\hline Cognate rate & 1245.3 & $<.001$ \\
Age & 42.2 & $<.001$ \\
Direction & .1 & .72 \\
Cognate rate $\|$ Age & 13.7 & $<.001$ \\
\hline
\end{tabular}


Table 4. Coefficients of the fixed effects together with standard errors and t-values for the model for the transformed data using z-scores.

\begin{tabular}{lcccr}
\hline & Estimate & Std. Error & t-value & \\
\hline (Intercept) & .56 & .02 & 45.92 & $* * *$ \\
Cognate rate & -1.03 & .03 & -35.30 & $* * *$ \\
Age & -.02 & .003 & -6.50 & $* * *$ \\
Direction & .003 & .02 & .36 & \\
Trial order & -.001 & .001 & -10.50 & $* * *$ \\
Session order & .01 & .006 & 1.53 & \\
PreviousResponse & .12 & .002 & 48.45 & $* * *$ \\
Cognate rate $\|$ Age & .02 & .005 & 3.70 & $* * *$ \\
\hline
\end{tabular}

Note. All flagged t-values are significant at the $\mathrm{p}<.001$ level.

The reference value for translation direction is Spanish-to-Basque. 


\section{Figures}

Figure 1. a) Distribution of participants per age. b) Distribution of items along the cognate continuum.
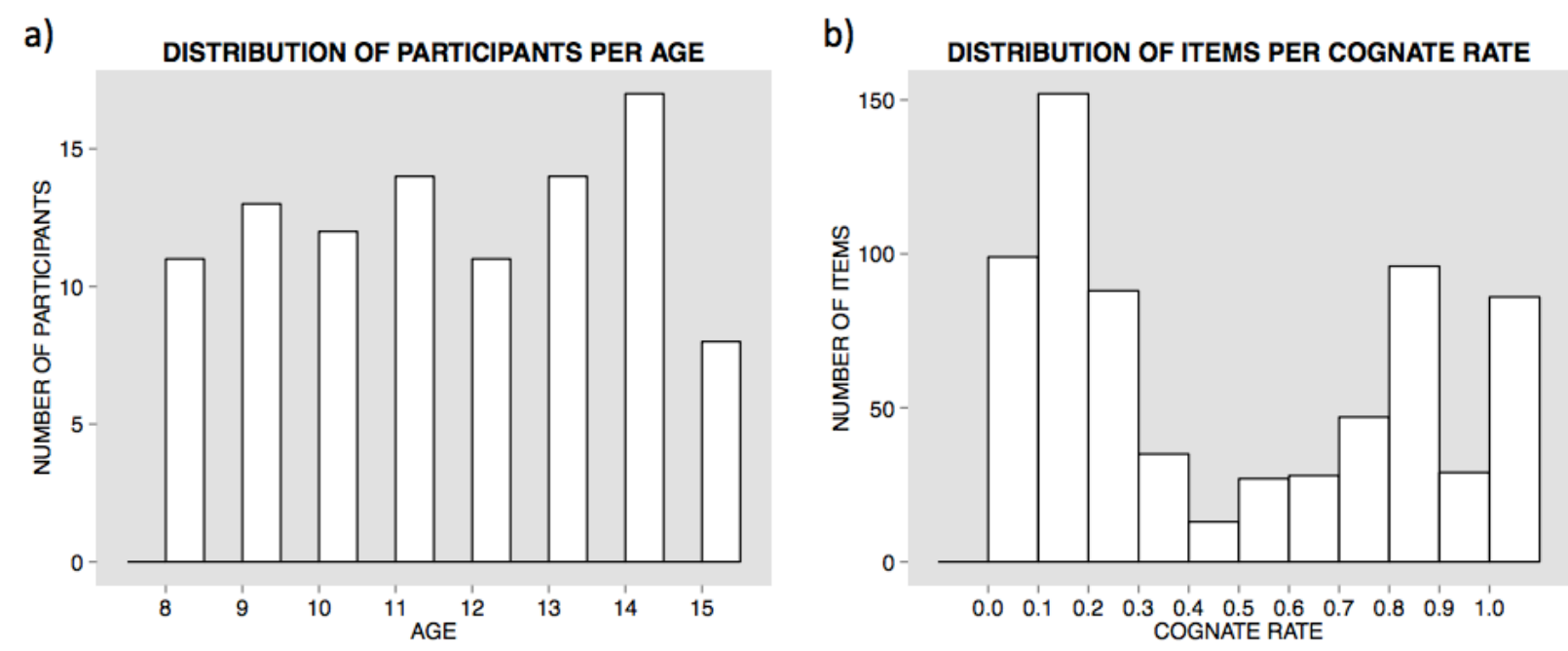
Figure 2. Schematic representation of a trial.

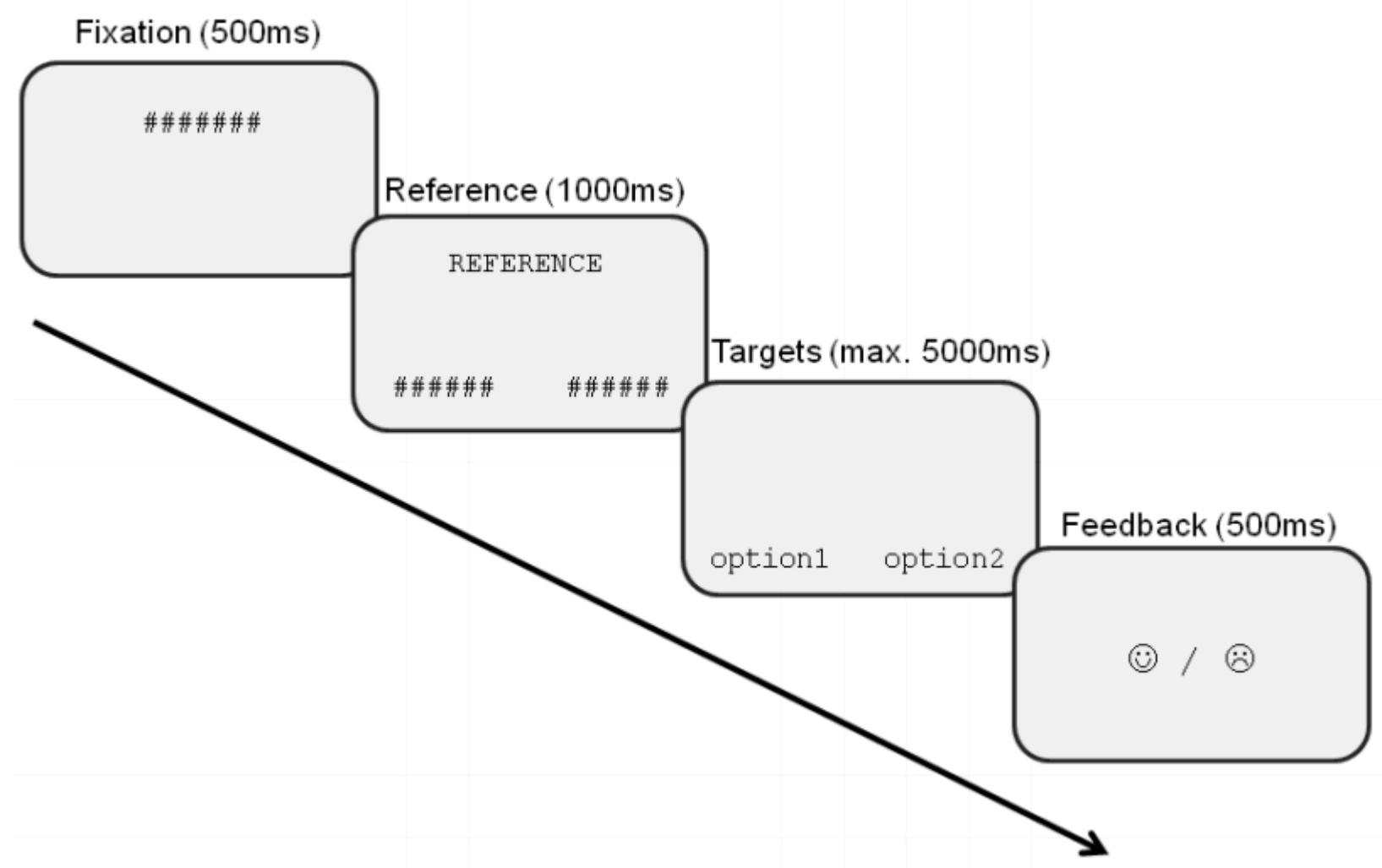


Figure 3. a) Estimated RTs for the continuous predictor Age for each translation direction (the predictor Age is represented mean-centered). b) Estimated RTs in the Spanish-to-Basque translation direction as a function of Age and Cognate Rate. c) Estimated RTs in the Basque-toSpanish translation direction as a function of Age and Cognate Rate. Cognate status refers to the orthographic overlap between translation equivalents as measured by the length-corrected Levenshtein distance (continuous predictor where 1 corresponds to fully-overlapping words). The continuous predictor Age is plotted (for illustration purposes only) so that each colored line represents a unique set of age (from 8 to 15 ).
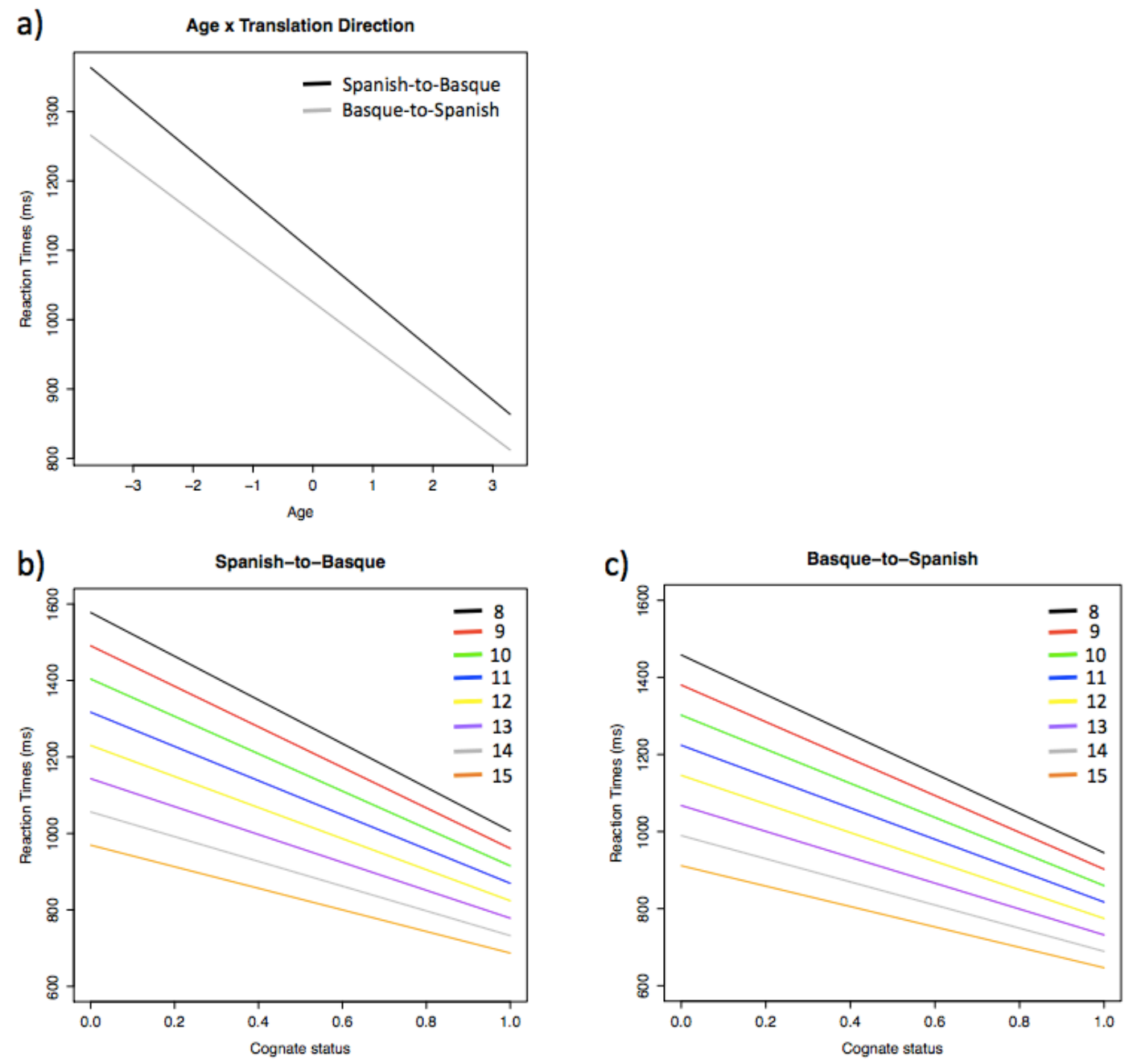
Figure 4. a) Estimated z-scores in the Spanish-to-Basque translation direction as a function of Age and Cognate Rate. b) Estimated z-scores in the Basque-to-Spanish translation direction as a function of Age and Cognate Rate.
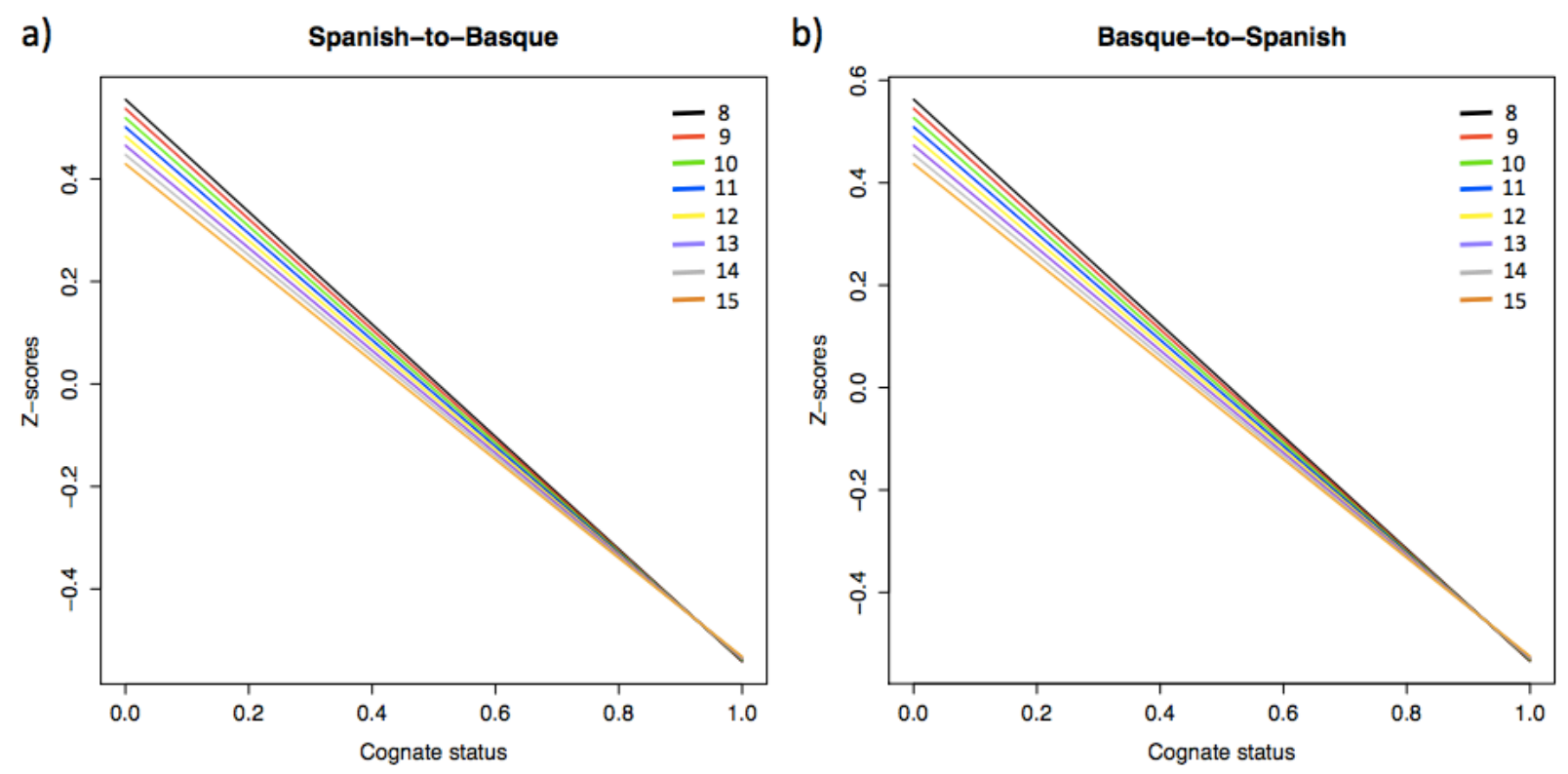